\title{
Smart integration of photovoltaic production, heat pumps and thermal energy storage in residential applications
}

\author{
Andrea L. Facci ${ }^{\mathrm{a}}$, Vesselin K. Krastev ${ }^{\mathrm{a}, *}$, Giacomo Falcucci ${ }^{\mathrm{b}, \mathrm{c}}$, Stefano Ubertini ${ }^{\mathrm{a}}$ \\ ${ }^{a}$ Department of Economics, Engineering, Society and Business Organization, University of Tuscia, 01100 Viterbo, Italy. \\ ${ }^{b}$ Department of Enterprise Engineering "Mario Lucertini", University of Tor Vergata, 00133 Rome, Italy. \\ ${ }^{c}$ John A. Paulson School of Engineering and Applied Sciences, Harvard University, 33 Oxford St., 02138 Cambridge - MA (USA).
}

\begin{abstract}
The optimal design of distributed generation systems is of foremost importance to reduce fossil fuel consumption and mitigate the environmental impact of human activities in urban areas. Moreover, an efficient and integrated control strategy is needed for each of the components of a distributed generation plant, in order to reach the expected economic and environmental performances.

In this paper, the transition from natural gas to electricity-based heating is evaluated for residential applications, considering the interplay between photovoltaic electricity produced on site and the thermal energy storage, to grant the optimal management of heating devices. The energy demand of an apartment building, under different climatic conditions, is taken as a reference and four power plant solutions are assessed in terms of energy cost and pollution reduction potential, compared to a baseline plant configuration. The performance of each power plant is analyzed assuming an optimized control strategy, which is determined through a graph-based methodology that was previously developed and validated by the authors. Outcomes from our study show that, if heat pumps are used instead of natural gas boilers, energy costs can be reduced up to $41 \%$, while $\mathrm{CO}_{2}$ emissions can be reduced up to $73 \%$, depending on the climatic conditions.

Our results provide a sound basis for considering the larger penetration of photovoltaic plants as an effective solution towards cleaner and more efficient heating technologies for civil applications. The simultaneous utilization of heat pumps (as substitutes of boilers) and photovoltaic panels yields a positive synergy that nullifies the local pollution, drastically cuts the $\mathrm{CO}_{2}$ emission, and guarantees the economical sustainability of the investment in renewable energy sources without subsidiary mechanisms.
\end{abstract}

Keywords: Photovoltaic heating, Heat pump, Thermal storage, Optimization, GHG

\section{Introduction}

The curtailment of energy consumption and green house gas (GHG) emissions are among the most relevant concerns for industrialized countries (UNFCCC, 2017; The European Parliament and the Council of the European Union, 2012).

In the last century, the worldwide Primary Energy Consumption (PEC) has constantly grown, reaching 13700 Mtoe/year in 2015, more than 2.5 times the PEC in 1971 (International Energy Agency, 2017a,b). In the same time span, the $\mathrm{CO}_{2}$ emissions have grown from $15500 \mathrm{Mton} /$ year in 1973 to $32300 \mathrm{Mton}$ in 2015. PEC and GHG emissions from countries not belonging to the Organisation for Economic Co-operation and Development (OECD) have sharply increased in the last decades, overwhelming the efforts of OECD countries towards a less energy intensive development (International Energy Agency, 2017b).

Despite more than 150 billion \$ per year are invested on energy efficiency (Eurostat, 2009), a wider effort is required to

\footnotetext{
*Corresponding author. Tel.: +390761357676.

Email addresses: andrea. facci@unitus. it (Andrea L. Facci), v.krasteveunitus.it (Vesselin K. Krastev), giacomo.falcucci@uniroma2.it (Giacomo Falcucci), stefano.ubertini@unitus.it (Stefano Ubertini)
}

meet the goal of keeping the global warming below $2^{\circ} \mathrm{C}$. According to the international energy agency (IEA) projections, following the actual energy policies, the world will consume about 18000 Mtoe emitting more than $36000 \mathrm{Mt}$ of carbon dioxide by 2014 (International Energy Agency, 2017a). However, by the same year, PEC should be lower than 15000 Mtoe to limit the average temperature increase below $2^{\circ} \mathrm{C}$. The GHG situation is even more critical, since $\mathrm{CO}_{2}$ emissions should not exceed $18500 \mathrm{Mt} / \mathrm{year}$ (International Energy Agency, 2017a), about a half compared to the forecast based on the actual trends. Furthermore, recent studies have clearly evidenced the alarming impact of high fine-particulate matter (PM) (Arden Pope III et al., 2009) and $\mathrm{NO}_{\mathrm{x}}$ (Anenberg et al., 2017) concentrations on human health, thus stressing the need for a substantial reduction of such class of emissions in urban areas.

Buildings are responsible for roughly $40 \%$ of energy demand in the European Union (EU) and United States (US) (European Commission, 2016; US Department of Energy, 2012). In particular, households cause $25 \%$ of the total green house gases emission related to fossil fuel combustion in the EU (European Environmental Agency, 2012). To mitigate their impact on both energy consumption and pollutant emissions, several technological alternatives are available in terms of energy generation systems, such as: i) an increase in the renewable energy 
penetration (Franco and Salza, 2011; Cozzolino et al., 2016; Lau et al., 2010); ii) distributed generation (DG) and cogeneration (CHP) or trigeneration (CHCP) (Onovwiona and Ugursal, 2006; Chicco and Mancarella, 2009; Jannelli et al., 2014a); iii) mechanical, electrical or thermal energy storage (Marano et al., 2012; Facci et al., 2014c; Jannelli et al., 2014b). Regarding DG, the definition of (Ackermann et al., 2001) should be taken as a reference, that is an electric power source connected directly to the distribution network or on the customer site of the meter. Such definition is independent from the specific generation technology, which might include renewable or fossil fuel sources, as well as electric-only or CHP generation devices.

Despite the growing concerns regarding energy sources depletion and air pollution in urban areas, combustion of fossil fuels is still a major source for residential applications (Balaras et al., 2005; Dodds et al., 2015). Unavoidably, fossil fuel combustion is also a significant source of local pollutants including $\mathrm{NO}_{\mathrm{x}}, \mathrm{CO}, \mathrm{PM}$ and Volatile Organic Compounds (VOC) in densely populated areas (Balaras et al., 2005). This is true even in the case of relatively clean gaseous fuels, such as Natural Gas (NG), due to uncontrolled combustion operation of typical residential-size burners. On the other hand, electricity based heating has no local emissions and could significantly contribute to improve the air quality in cities, to increase the efficiency of buildings (Youssef et al., 2017; Jonas et al., 2017; $\mathrm{Li}$ and Kao, 2017), and facilitate the penetration of renewable energy sources (RES) (Fraga et al., 2017). Nevertheless, such systems might increase the PEC and GHG emissions where electricity production largely relies on fossil fuels (e.g. Italy or Greece). In these situations, the switch from boilers to heat pumps should come together with an increased penetration of renewable energy production.

The introduction of DG plants based on RES is significantly contributing to the reduction of the GHG emission in all industrialized countries (Balke, 2014; European Environment Agency, 2014, 2015). Photovoltaic systems (PVs) are a very attractive RES solution (Jelle et al., 2012; Peng et al., 2011) and building integrated PVs are particularly well suited for DG systems and domestic applications (Jelle et al., 2012). Nevertheless, due to large investment costs, RES deployment largely relies on subsidiary mechanisms that, in turn, could increase the energy costs (Ragwitz and Steinhilber, 2014; Frondel et al., 2010). Moreover, the temporal mismatch between energy demand and the intermittent production of RES increases the imbalance of the national grids and thus the costs related to the infrastructure (Paatero and Lund, 2007).

Energy storage technologies promote the RES penetration, by facilitating the self consumption of the locally produced electricity, by increasing its values and by mitigation of the negative externalities (Kaldellis and Zafirakis, 2007; Beaudin et al., 2010; Poullikkas, 2013). In fact, in presence of a sufficient storage capacity, renewable energy from distributed generation plants can be stored during peak production hours to be utilized during high demand hours rather then being sold to the grid or wasted. Besides increasing the overall efficiency and reducing the impact of renewable installations on the grid the energy storage systems also increase the income of RES based DG plants.
For instance, in case of electricity, self-consumed energy has the economic value of the acquired electricity, which is 3 to 4 times larger compared to the price of electricity sold to the grid (GME, 2016).

Electricity storages are costly, require a non negligible maintenance and have a limited useful life (Poullikkas, 2013; Hittinger et al., 2012). On the other hand, thermal storages are relatively inexpensive, reliable and does not require specific maintenance (IEA-IRENA, 2013; Navarro et al., 2016a). In particular, residential applications require low temperature energy (i.e in the range $\left[50^{\circ} \mathrm{C}-80^{\circ} \mathrm{C}\right]$ ) and can thus utilize sensible heat thermal storage systems (Arteconi et al., 2013). Stratified hot water tanks are a viable technology for such applications (Arteconi et al., 2013), have a storage capacity comprised between $60 \mathrm{kWh} / \mathrm{m}^{3}$ and $80 \mathrm{kWh} / \mathrm{m}^{3}$ (Navarro et al., 2016a) and a cost in the range $\left[0.1 € / \mathrm{m}^{3}, 10 € / \mathrm{m}^{3}\right]$ (IEA-IRENA, 2013). Other storage media, such as phase change materials or chemical storage have a higher energy density but also a higher specific cost (Navarro et al., 2016a; Hasnain, 1998). Thereof, the optimal coupling of PV electricity production, electrical heating through heat pumps and thermal storage could be a viable solution to facilitate RES penetration, reduce the impact of subsidiary mechanisms on energy tariffs and cut down pollutant emissions in urban areas.

In this paper we study the conditions that promote establishing a positive synergy between PV production, electricity based heating and thermal energy storage as function of the energy demand, climatic conditions, and energy prices.

The working conditions (i.e the control strategy and the environmental conditions) determine the effectiveness of an energy systems as much as the design performance of its components (Onovwiona and Ugursal, 2006; Hawkes and Leach, 2007; Fabrizio et al., 2009; Andreassi et al., 2009; Chiappini et al., 2011; Facci et al., 2014a,b; Tribioli et al., 2016). Therefore, implementing a proper control strategy is crucial to achieve the expected benefits from DG systems. Similarly, the assessment of their performance cannot rely on the components design data, and realistic working conditions must be assumed. Following this, we adopt an optimization methodology, previously introduced and validated by the authors (Facci et al., 2014a,b,c; Cappa et al., 2015; Facci et al., 2015, 2016) to determine the optimal management for all the considered plant configurations, to correctly evaluate their effectiveness and to identify the conditions that promote the sought synergy.

The paper is organized as follows. In section 2 we describe the considered plant configurations, the energy demand, the assumed energy prices and all the relevant boundary conditions. In section 3 we briefly report the methodology employed to determine the plant control strategy and to evaluate the performance of the considered plants. The results are reported and analyzed in section 4. Finally, conclusions are drawn in section 5 .

\section{Problem statement}

In this paper we investigate the effectiveness of different energy systems to fulfill a residential energy demand in terms of 
local pollutant and GHG emissions, and of economic performance. In particular, we seek to demonstrate that the transition from NG to electricity-based space heating could effectively contribute to the improvement of air quality in urban areas and to the reduction of GHG emissions, thus encouraging a larger penetration of Photovoltaic (PV) electricity production. Moreover, we dissect the role of the thermal energy storage (TES) to improve the efficiency of such an energy system by effectively coupling PV electricity production and thermal demand.

\subsection{Energy demand}

The hourly electricity, heat, and chilling energy demands are available in the "commercial reference buildings" database (Office of Energy Efficiency and Renewable Energy, 2016) of the US Department of Energy (DOE) for 16 commercial reference buildings and for more than 1,000 locations (i.e. different climatic conditions). We selected the "Midrise Apartment" building whose principal features are reported in Table 1.

\begin{tabular}{cccc}
\hline Surface & Floors & Apartments & Offices \\
$3,135 \mathrm{~m}^{2}$ & 4 & 31 & 1 \\
\hline
\end{tabular}

Table 1: Relevant properties of the selected building (Office of Energy Efficiency and Renewable Energy, 2016)

The ambient temperature influences both the energy demand and the performance of energy converters. To highlight the effect of the environmental conditions, we consider three different climates, according to the IEA classification (Laustsen, 2008): heating based, moderate, and cooling based climate. The IEA classifies the climatic conditions according to the total number of heating degrees days (HDD) and cooling degrees days (CDD) per year, as reported in Table 2. Therein, we also report a representative city for each climate (Tsikaloudaki et al., 2011).

\begin{tabular}{c|ccccc}
\hline Climate & \multicolumn{2}{|c}{ HDD } & \multicolumn{2}{c}{ CDD } & City \\
& Min & Max & Min & Max & \\
\hline Heating based & 2,000 & $\infty$ & 500 & 1,000 & Milan \\
Moderate & 0 & 2,000 & 0 & 1,000 & Malaga \\
Chilling based & 1,000 & 2,000 & 1,000 & $\infty$ & Athens \\
\hline
\end{tabular}

Table 2: Heating and cooling degrees days per year and representative city for the considered climatic conditions (Laustsen, 2008).

The minimum $\left(T_{\min }\right)$ and maximum ambient temperature $\left(T_{\max }\right)$ registered throughout the year, influence both the energy demand and the design of the air conditioning systems. Such temperatures are retrieved from the typical meteorological year (TMY) for each of the considered locations (Photovoltaic geographical information system , 2017) and reported in Table 3.

Figure 1 schematically represents the energy demand for the chosen residential building, according to the different climatic conditions. The electricity demand is not influenced by the climatic condition, while the external temperature significantly influence the heat and chilling requests. The base load is relevant only for the electricity demand (about $15 \mathrm{~kW}$ out of a

\begin{tabular}{l|ccc}
\hline & Chilling based & Moderate & Heating based \\
\hline$T_{\min }$ & $-5^{\circ} \mathrm{C}$ & $5^{\circ} \mathrm{C}$ & $2.5^{\circ} \mathrm{C}$ \\
$T_{\max }$ & $33^{\circ} \mathrm{C}$ & $27^{\circ} \mathrm{C}$ & $31^{\circ} \mathrm{C}$ \\
\hline
\end{tabular}

Table 3: Minimum and maximum ambient temperature for three climatic conditions: chilling based, moderate and heating based.

maximum load of of about $50 \mathrm{~kW}$ ), while it is negligible for the heat and cold requests.

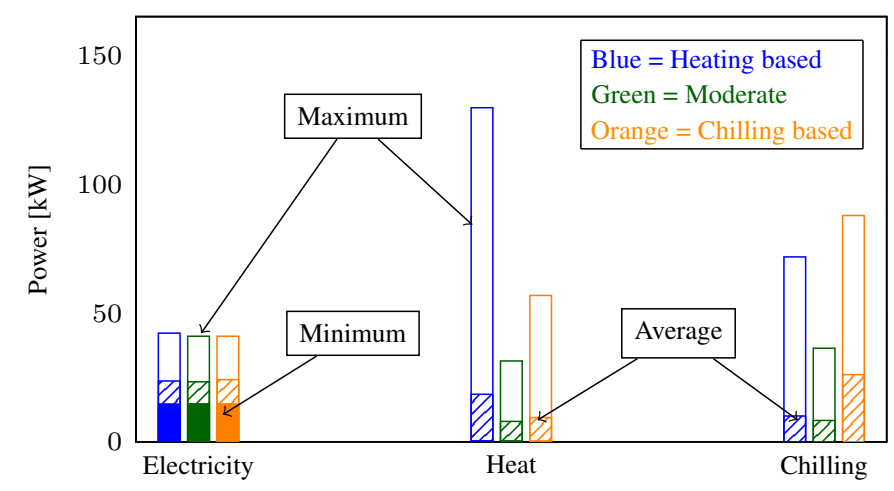

Figure 1: Minimum, average, and maximum energy demand for a midrise apartment building in all the climatic conditions. The filled portion of vertical bars represents the minimum (base load) demand, the line-pattern portion represents the average demand while the empty portion represents the maximum (peak) demand. Data are retrieved from (Office of Energy Efficiency and Renewable Energy, 2016).

For clarity, only the maximum, average, and minimum demands are reported in Figure 1. However, the instantaneous energy requests, reported by (Office of Energy Efficiency and Renewable Energy, 2016), have been employed in the present analysis.

\begin{tabular}{c|cc}
\hline & Electricity & Natural gas \\
\hline Heating based & $0.2427 € / \mathrm{kWh}$ & $21.80 € / \mathrm{GJ}$ \\
Moderate & $0.2235 € / \mathrm{kWh}$ & $21.31 € / \mathrm{GJ}$ \\
Chilling based & $0.1720 € / \mathrm{kWh}$ & $16.90 € / \mathrm{GJ}$ \\
\hline
\end{tabular}

Table 4: Energy prices for all the considered climatic conditions. Data are retrieved from (Eurostat, 2016).

The reference cities for each climatic condition are located in different European countries, as evidenced in Table 2. Each climate has a peculiar energy price, as highlighted in Table 4. Energy prices in each country are retrieved from the Eurostat database (Eurostat, 2016).

Despite several European countries promote the selling of renewable electricity through feed in tariffs and other subsidiary mechanisms, we assumed that electricity eventually produced in excess by the PV field is not remunerated by the grid. This assumption allows to identify the conditions that promote the self-consumption of electrical power locally produced by the $\mathrm{PV}$, thus minimizing the impact of RES production on the electrical grid. The study of such conditions would be hindered by the high revenues yielding from subsidiary electricity tariffs. 


\subsection{Power plant configurations}

We considered 5 possible power plants (including the reference case) that are characterized by different technologies for the production of thermal energy. In particular, the effects of TES and PV energy production are considered, as summarized in Table 5 and in Figure 2. The reference case represents the baseline state of art of thermal production in residential installations. Specifically a condensing natural gas boiler satisfies the thermal demand. Also case A utilizes such a technology. Vapor compression heat pumps (HP) are considered as an alternative to condensing natural gas boilers for heat production in cases B, C, and D. The the considered model utilizes the R410A as refrigerant fluid and is equipped with 3 scroll compressors. An R410-A single stage, scroll compressor, vapor compression mechanical chiller is utilized in all the plant configurations. A sensible heat thermal energy storage that utilizes water as a storage medium is present in all the configuration except for case D. Despite we utilized a sensible heat storage, due to its low initial cost and technological reliability the presented methodology is general and can be applied also to phase change or chemical energy storages by simply varying the investment cost and, eventually, the round trip efficiency.

\begin{tabular}{c|ccccc}
\hline & Boiler & HP & PV & TES & Chiller \\
\hline Reference & $\checkmark$ & & & $\checkmark$ & $\checkmark$ \\
Case A & $\checkmark$ & & $\checkmark$ & $\checkmark$ & $\checkmark$ \\
Case B & & $\checkmark$ & & $\checkmark$ & $\checkmark$ \\
Case C & & $\checkmark$ & $\checkmark$ & $\checkmark$ & $\checkmark$ \\
Case D & & $\checkmark$ & $\checkmark$ & & $\checkmark$ \\
\hline
\end{tabular}

Table 5: Relevant energy conversion systems for each of the considered plant configurations.

Table 6 reports the rated power for all the plant subsystems as functions of the climatic conditions. The HP design power is generally higher compared to the boiler power and the difference is larger for colder climates. In fact, the lower is the external temperature, the lower is the power that the HP can effectively deliver (see Figure 3). The HPs are designed to satisfy the peak thermal demand at the lower external temperature of the TMY (see table 3) for each climatic condition.

\begin{tabular}{c|ccc}
\hline & \multicolumn{3}{|c}{ Maximum power [kW] } \\
& Chilling based & Moderate & Heating based \\
\hline Boiler & 130 & 35 & 60 \\
HP & 180 & 45 & 80 \\
Chiller & 75 & 50 & 95 \\
PV & 112 & 112 & 112 \\
TES & 130 & 35 & 60 \\
\hline
\end{tabular}

Table 6: Relevant energy conversion systems for each of the considered plant configurations at different climates.

Similar to the HPs, the chillers are designed to produce the peak chilling demand at the highest temperature for each climatic condition. Thus, their rated power is generally higher compared to the peak chilling request. In fact, the higher is the ambient temperature the lower are the Coefficient of Performance (COP) and the effective power of the chiller (see Figure 3).

The available surface for the PV field on the roof of the building is $A_{\mathrm{PV}}=750 \mathrm{~m}^{2}$, resulting in a peak rated power of $P_{\mathrm{PV}}=112 \mathrm{kWp}$. The peak value is obtained from the formula:

$$
P_{\mathrm{PV}}=P_{\mathrm{PTC}} A_{\mathrm{PV}}
$$

where $P_{\mathrm{PTC}}$ is the mono-crystalline $\mathrm{PV}$ module rating per unit area under PVUSA Testing Conditions (PTC) (Dows and Gough, 1996), according to the modules' manufacturer spec sheet (Mitsubishi Electric, 2017). Note that this corresponds to a PV system rated efficiency of $\eta_{\mathrm{PV}}=15 \%$.

The efficiency of all the energy converters varies as a function of the set-point, as reported in Figure 4. We note that low load operation (below 40\%) is particularly critical for all the energy systems. Therefore, the TES option is considered (see Table 5) to release the boiler and the HP from strict thermal tracking. Note that TES technologies have already been widely recognized as one of the most feasible options to increase the energy efficiency in buildings (Arce et al., 2011; Navarro et al., 2016a,b). In our case, the power that can be delivered by the TES is always equal to the peak thermal request and its capacity is assumed equal to 3 equivalent hours. The TES effectiveness is measured through its round trip efficiency

$$
\eta_{\mathrm{TES}}=\frac{E_{\mathrm{in}}}{E_{\mathrm{out}}},
$$

where $E_{\text {in }}$ is the energy introduced in the reservoir and $E_{\text {out }}$ is the energy that can be extracted. The round trip efficiency of the TES is assumed to be $\eta_{\text {TES }}=0.9$ (Facci et al., 2014c).

\section{Methodology}

The effective plant efficiency is largely determined by its control strategy (Onovwiona and Ugursal, 2006; Hawkes and Leach, 2007; Fabrizio et al., 2009; Andreassi et al., 2009; Chiappini et al., 2011; Facci et al., 2014a,b; Tribioli et al., 2016). Thereafter, we compare the performances of the different configurations assuming an optimized control strategy that is obtained through the methodology introduced in (Facci et al., 2014b), and further developed in (Facci et al., 2014c) and (Facci et al., 2014a). Such a methodology minimizes a prescribed objective function accounting for: (i) the design performances of all the subsystems; (ii) the derating of the performances at part load; (iii) the effects of environmental conditions; (iv) energy demand and costs as functions of time; (v) maintenance and cold start costs; (vi) constraints related to the dynamic behavior of the equipment, such as the minimum time interval between two consecutive starts or shutdowns.

All the energy converters are modeled as black-boxes, through their efficiency curves as functions of the set-point and the environmental conditions. Specifically, the power output of the $i$-th subsystem at time $t$ is calculated as:

$$
p_{i}(t)=s_{i}(t) p_{i}^{*} \alpha_{i}(t)
$$


(a) Reference case

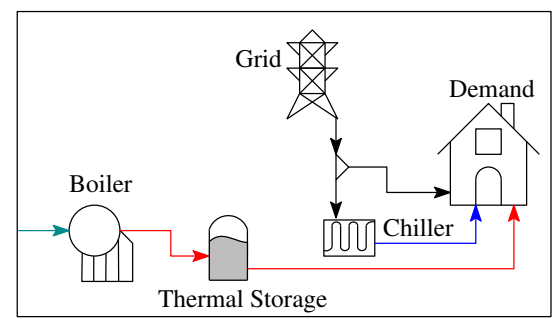

(d) Case C

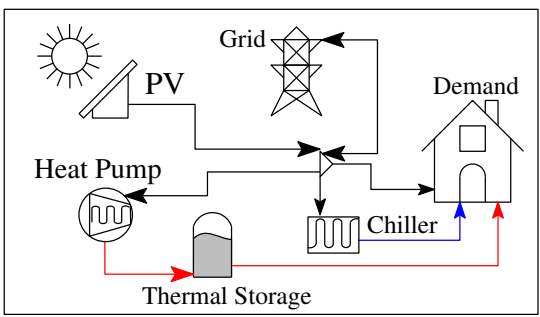

(b) Case A

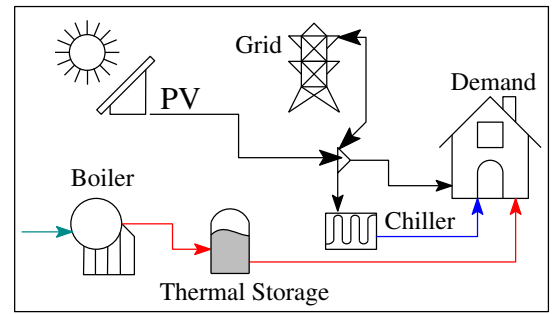

(e) Case D

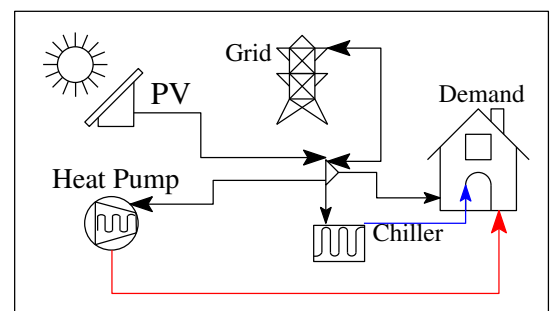

(c) Case B

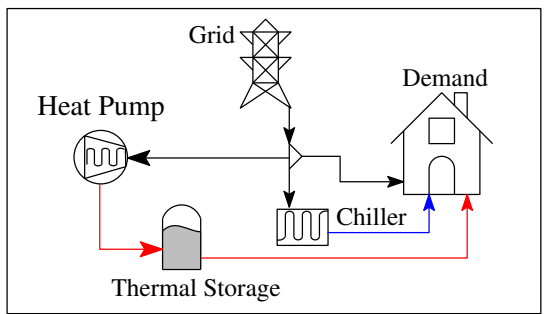

(f) Energy Flows Legend

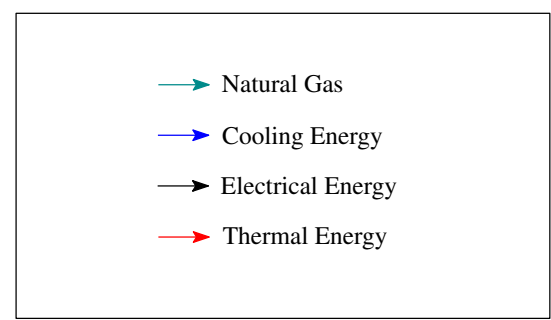

Figure 2: Schematics of the considered power plant configurations: (a) Reference case; (b) Case A; (c) Case B; (d) Case C; (e) Case D; (f) Legend of the relevant energy streams.

(a) Chiller

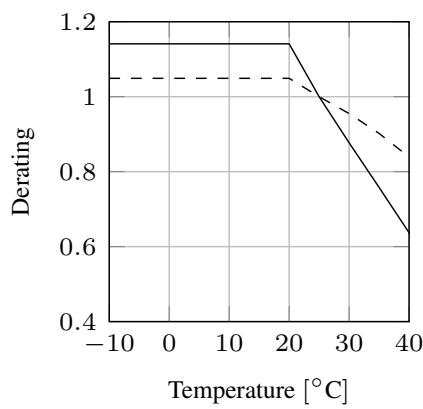

(b) Heat pump

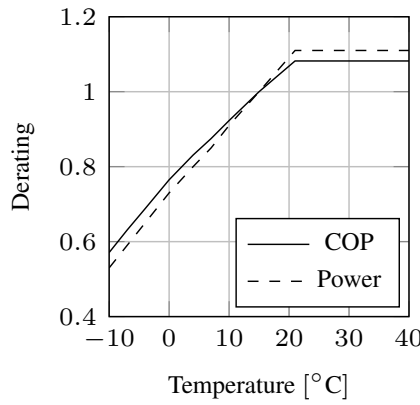

Figure 3: Performance derating as function of the environment temperature for the chiller and the heat pump. The reference temperature is $15^{\circ} \mathrm{C}$. Data retrieved from (Daikin, 2015).

(a) Heat pump

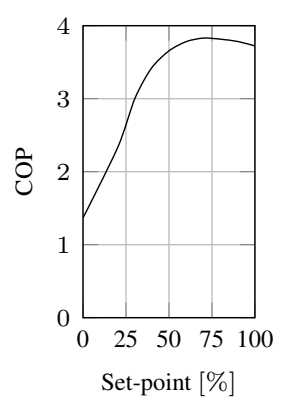

(b) Boiler

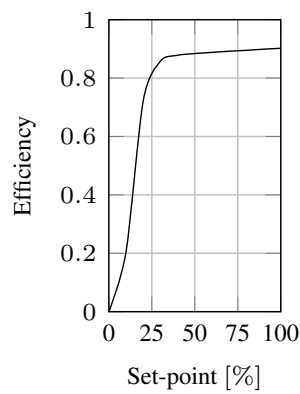

(c) Chiller

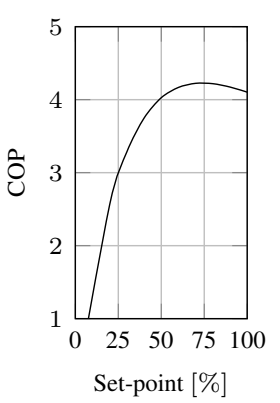

Figure 4: Efficiency of the considered energy systems as functions of the setpoint. Data retrieved from (Fabrizio et al., 2009).

where $s_{i}(t)$ is the set-point, $p_{i}^{*}$ is the design power, and $\left.\alpha_{(} t\right)$ is the power derating coefficient, that is function of the environmental temperature, pressure, and altitude. The corresponding

required input power is:

$$
u_{i}(t)=\frac{s_{i}(t) p_{i}^{*} \alpha_{i}(t)}{\eta_{i}\left(s_{i}(t)\right) \beta_{i}(t)}
$$

where $\eta_{i}\left(s_{i}(t)\right)$ is the efficiency, and and $\left.\beta_{(} t\right)$ is the efficiency derating coefficient, that is function of the environmental temperature, pressure, and altitude. Note that the problem is nonlinear, since the efficiency is a function of $s(t)$.

Economic optimization is performed through the following objective function:

$$
\begin{array}{r}
G_{\text {Cost }}=\sum_{h=1}^{8760} C_{f}(h, s(h))+C_{m}(h, s(h))+ \\
+C_{s}(h, s(h))-R(h, s(h)),
\end{array}
$$

being $h$ the time interval, $C_{f}$ the cost of fuel, $C_{m}$ the maintenance cost, $C_{s}$ the cold-start cost, and $R$ the revenue/cost yielding from the electricity exchanged with the grid. Costs are functions of the time interval and the plant state (i.e. the set-point of the subsystems) $s(h)$.

Equation (5) is subject to constraints related to the energy flows and to the dynamic behavior of the plant subsystems. The thermal energy balance reads:

$$
U_{\mathrm{th}}-P_{\mathrm{th}}+P_{\mathrm{st}} \geq 0
$$

where $U_{\text {th }}$ is the thermal energy demand, $P_{\text {th }}$ is the heating power produced by the energy converters within the plant, and $P_{\text {st }}$ is the the thermal power of the heat storage. Noter that, $U_{\text {th }}$ and $P_{\mathrm{th}}$ are positive, while $P_{\mathrm{st}}$ is positive when the system is storing energy and negative when it is releasing the heat. The cooling energy balance reads:

$$
U_{\mathrm{co}}-P_{\mathrm{co}} \geq 0
$$


being $U_{\text {co }}$ and $P_{\text {co }}$ the cooling power demand and production respectively. The system of eqs. (8) represents the constraint related to the dynamic behavior of the subsystems.

$$
\left\{\begin{array}{l}
\text { if } \tau_{i}(t)<\tau_{i}^{*} \text { and } s_{i}(t-1)>0 \rightarrow s_{i}(t)>0 \\
\text { if } \theta_{i}(t)<\theta_{i}^{*} \text { and } s_{i}(t-1)=0 \rightarrow s_{i}(t)=0
\end{array}\right.
$$

where $t$ is the time interval, $s_{i}(t)$ is the set-point of the $i$-th energy system, $\tau_{i}$ is the time spent since the last cold start, and $\tau_{i}^{*}$ is the minimum time interval between two consecutive cold starts. Similarly, $\theta_{i}(t)$ is the time spent since the last shut down and $\theta_{i}^{*}$ is the minimum interval between two consecutive shut downs.

Equation (5) is discretized with respect to the plant state and in time, and the problem is represented as a weighted and oriented graph. The optimal control strategy is determined by seeking for the shortest path across the graph. The reader can refer to (Facci et al., 2014a,b,c) for more details on the optimization methodology.

Having determined the optimal control strategy, that is the set-point of the subsystems for all the time steps, the global performance parameters are easily calculated.

Economic performance is evaluated through the total cost, retrieved through eq. (5) and through the Pay Back Period (PBP), that is given by:

$$
\mathrm{PBP}=\frac{I-I_{\mathrm{Ref}}}{C-C_{\mathrm{Ref}}},
$$

where $C$ and $C_{\text {ref }}$ are the global cost of the considered case and of the reference case respectively, $I$ is the initial investment and $I_{\text {ref }}$ is the capital cost of the reference scenario. For each of the considered cases, the initial investment is calculated as,

$$
I=I_{\mathrm{HP}}+I_{\mathrm{Boi}}+I_{\mathrm{PV}}+I_{\mathrm{TES}},
$$

where the cost of HP $I_{\mathrm{HP}}$ and of the boiler $I_{\mathrm{Boi}}$ are estimated as (Fabrizio et al., 2009):

$$
\begin{aligned}
& I_{\mathrm{HP}}=579\left(P_{\mathrm{HP}}\right)^{0.79} \\
& I_{\mathrm{Boi}}=510\left(P_{\mathrm{Boi}}\right)^{0.61},
\end{aligned}
$$

where $P_{\mathrm{HP}}$ and $P_{\mathrm{Boi}}$ are the design power of the boiler and the $\mathrm{HP}$ respectively. The cost of the PV field is:

$$
I_{\mathrm{PV}}=i_{\mathrm{PV}} P_{\mathrm{PV}}
$$

being $i_{\mathrm{PV}}$ the specific capital cost required to install $1 \mathrm{kWp}$ of PV panels, that includes the cost of the PV modules and the balance of system (BOS) and $P_{\mathrm{PV}}$ the peak power of the photovoltaic system. According to (Candelise et al., 2013) the BOS represents between $50 \%$ and $65 \%$ of the total installed cost of grid connected PV systems. Here, we assume that $i_{\mathrm{PV}}=$ $1200 € / \mathrm{kWp}$ for a PV field in the power range $[100 \mathrm{~kW}, 200 \mathrm{~kW}]$ (Tilli et al., 2017; Paul, 2017; UNEF, 2017). The investment cost of the thermal storage is

$$
I_{\mathrm{TES}}=i_{\mathrm{TES}} Q_{\mathrm{TES}},
$$

where $Q_{\mathrm{TES}}$ is the TES capacity and $i_{\mathrm{TES}}$ is its specific cost. According to (IEA-IRENA, 2013), $0.1 € / \mathrm{kW}<i_{\text {TES }}<10 € / \mathrm{kW}$ and we safely assumed that $i_{\text {TES }}=10 € / \mathrm{kW}$. Note that we discarded the costs of those components that are common to all the scenarios for this comparative analysis. Thereafter, the capital cost of the reference scenario is $I_{\text {ref }}=I_{\text {Boi }}+I_{\text {TES }}$.

Carbon dioxide emissions are calculated through the following equation,

$$
m_{\mathrm{CO}_{2}}=\sum_{i=1}^{N_{\text {fuel }}}\left(m_{i} k_{i}\right)+E_{\text {grid }} k_{\text {grid }}
$$

where $N_{\text {fuel }}$ is the number of different fuels utilized in the plant, $m_{i}$ is the mass of the $i-$ th fuel, $k_{i}$ is its $\mathrm{CO}_{2}$ emission factor, $E_{\text {grid }}$ is the electrical energy exchanged with the grid, and $k_{\text {grid }}$ is the carbon dioxide intensity of the grid. The emission factors of natural gas $\left(K_{\mathrm{NG}}\right)$ and grid electricity, retrieved from (Sari and Bayram, 2014) and from (Moro and Lonza, 2017), respectively, are reported in Table 7.

\begin{tabular}{c|cc}
\hline & $k_{\mathrm{NG}}$ & $k_{\text {grid }}$ \\
\hline Heating based & $0.1998 \mathrm{~kg} / \mathrm{kWh}$ & $0.433 \mathrm{~kg} / \mathrm{kWh}$ \\
Moderate & $0.1998 \mathrm{~kg} / \mathrm{kWh}$ & $0.341 \mathrm{~kg} / \mathrm{kWh}$ \\
Chilling based & $0.1998 \mathrm{~kg} / \mathrm{kWh}$ & $0.767 \mathrm{~kg} / \mathrm{kWh}$ \\
\hline
\end{tabular}

Table 7: Natural gas and electricity carbon intensities as functions of the climatic condition. Data retrieved from (Moro and Lonza, 2017) for the electricity and from (Sari and Bayram, 2014) for natural gas.

Fuel burners are also sources of local pollutants such as $\mathrm{NO}_{\mathrm{x}}, \mathrm{CO}, \mathrm{VOC}, \mathrm{SO}_{\mathrm{x}}$ and PM. The emitted mass of the generic pollutant species $m_{x}$ can be calculated as

$$
m_{x}=\sum_{j=1}^{N_{\text {comb }}}\left(E_{j} \Psi_{j, x}\right)
$$

where $N_{\text {comb }}$ is the number of combustion sources (e.g. fuel boilers, internal combustion engines, etc), $E_{j}$ is the energy input for the $j-$ th combustion source, and $\Psi_{j, \mathrm{x}}$ is its emission factor for the species $x$. The emission factors for natural gas burners are reported in Table 8 (United States Environmental Protection Agency, 2017)

\begin{tabular}{ccc}
\hline Pollutant species & \multicolumn{2}{c}{ Emission factor } \\
\hline $\mathrm{NO}_{\mathrm{x}}$ & $3.974 \times 10^{-5}$ & $\mathrm{~kg} / \mathrm{MJ}$ \\
$\mathrm{CO}$ & $1.680 \times 10^{-5}$ & $\mathrm{~kg} / \mathrm{MJ}$ \\
$\mathrm{VOC}$ & $2.309 \times 10^{-6}$ & $\mathrm{~kg} / \mathrm{MJ}$ \\
$\mathrm{SO}_{\mathrm{x}}$ & $2.519 \times 10^{-7}$ & $\mathrm{~kg} / \mathrm{MJ}$ \\
$\mathrm{PM}$ & $3.190 \times 10^{-6}$ & $\mathrm{~kg} / \mathrm{MJ}$ \\
\hline
\end{tabular}

Table 8: Emission factor for the relevant local pollutants for natural gas burners and furnaces according to the data reported in (United States Environmental Protection Agency, 2017)

\section{Results and discussion}

Cases $\mathrm{A}$ and $\mathrm{C}$ are the only power plant configurations which include both PV electricity generation and the thermal storage, while the thermal storage is also present in the reference configuration and in Case B. 


\subsection{Identification of the optimal plant configuration}

Figure 5 reports the yearly operative cost (OPEX) for all cases and for all the considered climatic conditions. Case $\mathrm{C}$ always yields the minimum cost thanks to the simultaneous presence of PV, TES and HPs for heating. Specifically, this configuration reduces the OPEX by $35 \%$ for the heating based climate, by $41 \%$ for the moderate climate and by $40 \%$ for the chilling based climate with respect to the reference cases.

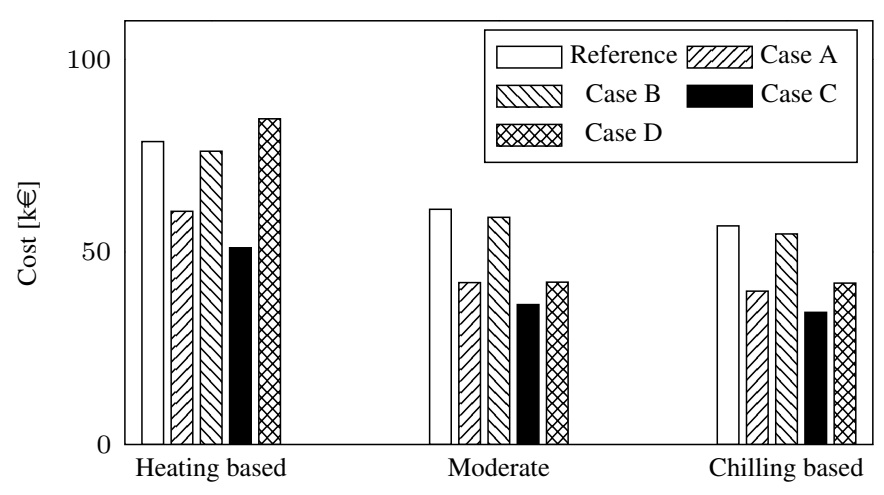

Figure 5: Yearly operative cost for the considered power plant as a function of the climatic condition and of the unit energy costs.

The utilization of the PVs without the HPs (Case A) reduces the OPEX by $23 \%$ for the heating based climate, by $31 \%$ for the moderate climate and by $30 \%$ for the chilling based climate. Nevertheless, the usage of boilers instead of HPs does not allow to take full advantage from the PV installation. Compared to Case C, the OPEX of Case A is $18 \%$ higher for heating based climate, and $16 \%$ higher for heating based and moderate climates. Notably, has a minor impact on the cost difference between Case $\mathrm{A}$ and Case $\mathrm{C}$ despite the warmer is the temperature, the larger is the efficiency of the HP (see Figure 3) and the PVs produce more electricity.

In case $\mathrm{B}$, the utilization of HPs in substitution of traditional boilers, without introducing further RES does not yield significant economical benefits. In particular, for the heating based climate the OPEX decreases by $3.2 \%$ compared to the reference case. For moderate and chilling based cases, the OPEX is reduced by $3.4 \%$ and $3.7 \%$, respectively. Comparing the ratio $\xi=c_{\mathrm{el}} / c_{\mathrm{NG}}$ between the electricity $\operatorname{cost}\left(c_{\mathrm{el}}\right)$ and the natural gas cost $\left(c_{\mathrm{NG}}\right)$ to $\gamma=\overline{\mathrm{COP}_{\mathrm{HP}}} / \overline{\eta_{\text {boi }}}$, explains such a trend. Here, $\gamma$ is calculated through effective working conditions of the HP and the boilers rather than utilizing design data. In fact, the average COP of the HP is estimated as:

$$
\overline{\mathrm{COP}_{\mathrm{HP}}}=\frac{E_{\mathrm{th}, \mathrm{HP}}}{U_{\mathrm{el}, \mathrm{HP}}}
$$

where $E_{\mathrm{th}, \mathrm{HP}}$ is the total cooling energy delivered by the HP throughout the year and $U_{\mathrm{el}, \mathrm{HP}}$ is the corresponding required electrical energy. Similarly, the average efficiency of the boiler is:

$$
\overline{\eta_{\mathrm{boi}}}=\frac{E_{\mathrm{th}, \mathrm{boi}}}{U_{\mathrm{boi}}}
$$

where $E_{\text {th,boi }}$ is the total cooling energy delivered by the boiler throughout the year and $U_{\text {boi }}$ is the corresponding required in- put energy. Note that, $\gamma$ and $\xi$ are close for all the considered cases. However, for the heating based case $\xi=3.09$ and is larger compared $\gamma=3.78$. On the contrary, $\gamma>\xi$ for the other climatic conditions. Specifically, $\xi=2.92$ and $\gamma=4.37$ for the moderate climate and $\xi=2.83$ and $\gamma=4.24$ for the chilling based climates. As expected, the lower is $\xi$ the higher is the cash flow.

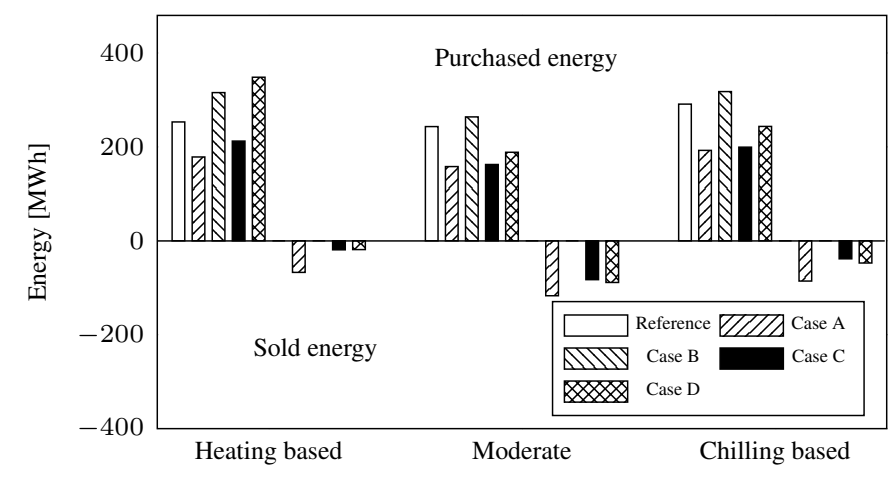

Figure 6: Electricity sold to and purchased from the grid for all the considered cases and climatic conditions. Purchased energy is positive and sold electricity is negative.

Comparing Case D to Case C elucidates the role of the TES in promoting the synergy between electrical heating and PVs. The OPEX of Case D (i.e without TES) is always higher compared to the one of Case C. In particular, the operative cost increases by $66 \%, 16 \%$, and $22 \%$ for heating based, moderate, and chilling based climate respectively. The absence of the TES has a twofold negative effect. First, the HP is forced to follow the heat demand, thus reducing its efficiency since the thermal demand is higher during the colder hours of the day. Second, since the heat demand and the PV production are not contemporary, the electricity consumed by the HP is largely retrieved from the grid, increasing the purchased electricity (see Figure 6). Both aspects are particularly critical for the heating based climate that has the lowest external temperature and the higher $\xi$. Notably, for heating based climate the electricity acquired and the OPEX of case D are higher compared to the Reference Case.

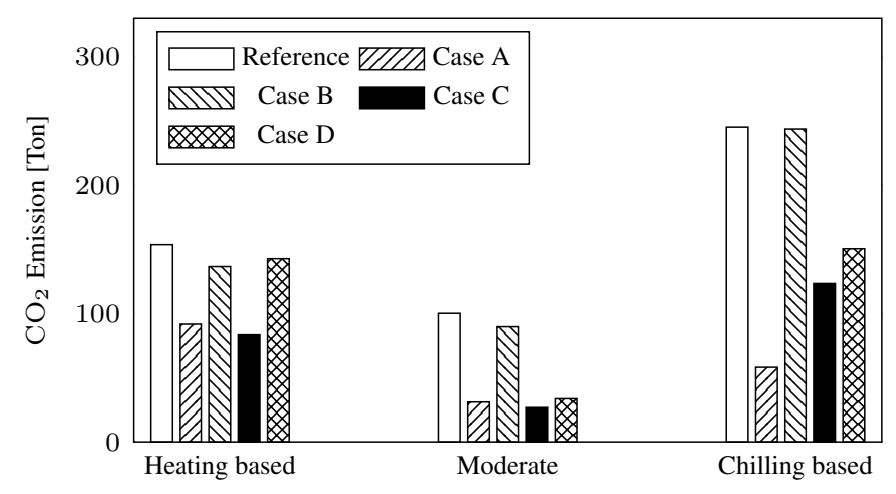

Figure 7: Carbon dioxide emission at different climatic conditions.

Figure 7 reports the $\mathrm{CO}_{2}$ emission for each power plant 
configuration and climatic condition. The average carbon dioxide emission factor for the boiler is $k_{\text {boi }}=k_{\mathrm{NG}} / \eta_{\text {boi }}$ and is equal to $0.22 \mathrm{~kg} / \mathrm{kWh}$ for all the considered climates. Figure 7 evidences that Case $\mathrm{C}$ delivers the lowest emission for the heating based and moderate climate reducing the $\mathrm{CO}_{2}$ emitted by $46 \%$ and by $73 \%$ respectively, compared to the Reference Case. In fact, according to the effective working conditions of the HP, the average carbon dioxide emission factor of the HP, $k_{\mathrm{HP}}=$ $k_{\text {grid }} / \mathrm{COP}$, is $0.13 \mathrm{~kg} / \mathrm{kWh}$ and $0.087 \mathrm{~kg} / \mathrm{kWh}$ for heating based and moderate climates respectively, and is much lower compared to $k_{\text {boi }}$. Thus, in these climates, Case $\mathrm{C}$ reduces $\mathrm{CO}_{2}$ emissions both with respect to the Reference Case and to Case A, despite Case $\mathrm{C}$ acquires $3 \%$ (moderate climate) to $20 \%$ (heating based climate) more electricity (See Figure 6) and sells 7\% (heating based climate) to $30 \%$ (moderate climate) less energy than Case A.

For the chilling based climate $k_{\text {grid }}$ is about twice than for heating based and moderate ones (see Table 7) thus increasing $k_{\mathrm{HP}}$ up to $0.20 \mathrm{~kg} / \mathrm{kWh}$. As a consequence, the advantage of substituting the boiler with the HP is limited. Moreover, the high $k_{\text {grid }}$ emphasizes the curtailment of $\mathrm{CO}_{2}$ emissions related to feeding the electricity produced through the PVs into the grid. Thus, Case A has the lowest emission for the chilling based condition, due to the larger amount of electricity sold to the grid (see Figure 6), 76\% lower with respect to the Reference Case. Case $\mathrm{C}$ reduces the $\mathrm{CO}_{2}$ emission by $50 \%$ compared to the Reference Case. Case B does not generate significant emission reduction regardless of the climatic condition, while Case $\mathrm{D}$ benefits from the PV installation in the moderate and chilling based climate scenarios.

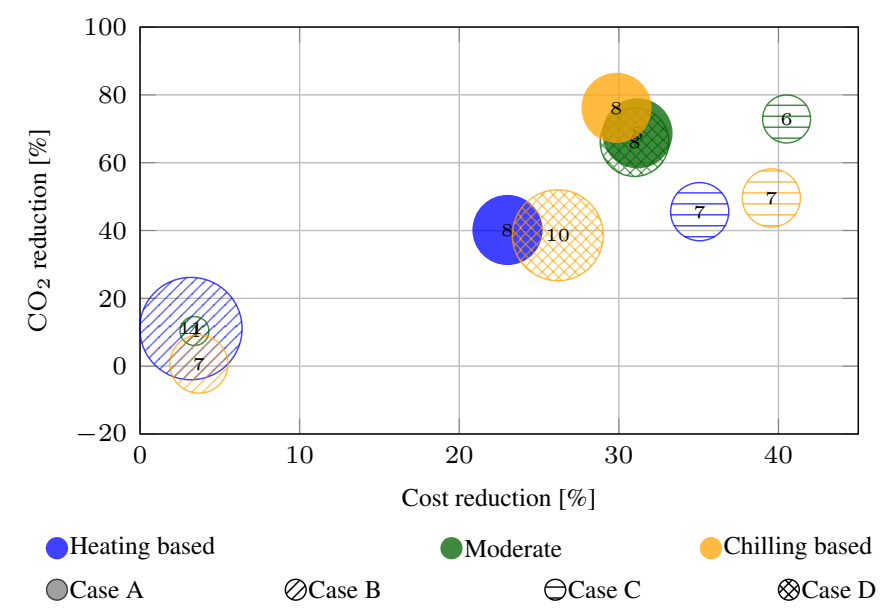

Figure 8: Comparison between the different scenarios: the area of the circles is proportional to the pay back period and the center of the circles defines relative cost and $\mathrm{CO}_{2}$ emission reduction. Cases $\mathrm{D}$ for the heating based climate has negative cash flow and is not represented since the PBP is not defined in this case.

A comprehensive evaluation of all the scenarios, in terms overall economic performance and GHG reduction potential, is presented in Figure 8.

Case B has the shortest PBP for moderate climate, but the impact on cost and GHG emission reduction is marginal. In this climate, Cases D and A double the PBP compared to Case B, but has a much larger effect on operative cost and GHG emissions. Similarly, for chilling based climate the PBP of Cases A and D is higher compared to Case B (that has the lowest PBP together with Case $\mathrm{C}$ ) but the cash flow and GHG reduction is much higher. On the contrary, for heating based climate Case B the highest PBP while PBP cannot be defined for heating based climate conditions due to the negative yearly cost performance. Cases $\mathrm{A}$ and $\mathrm{C}$ are the most attractive for all the considered performance parameters and in all climatic conditions. Nevertheless, Case $\mathrm{C}$ has always the shortest PBP, higher cash flow, and, limited to moderate and heating based climate conditions, also lower $\mathrm{CO}_{2}$ emission.

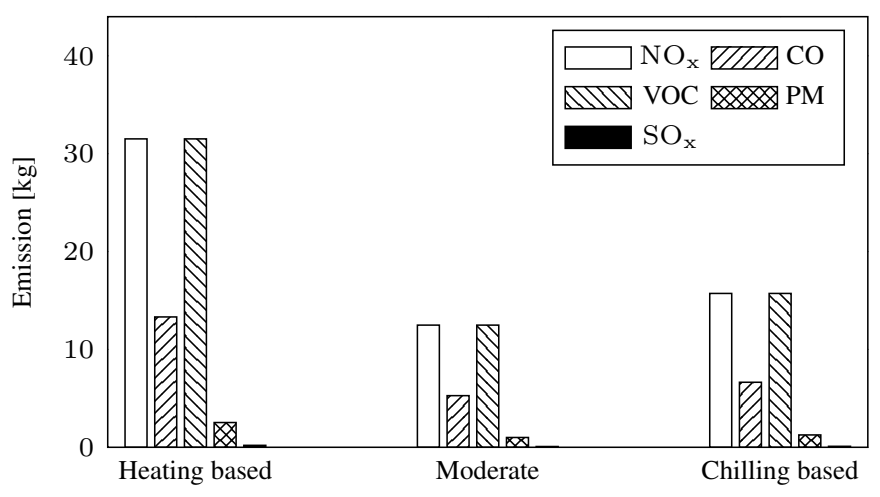

Figure 9: Local pollutant emissions for the reference plant and for Case A at different climatic conditions.

Moreover, Case $\mathrm{C}$ completely avoids local pollutant emissions (i.e. $\mathrm{NO}_{\mathrm{x}}, \mathrm{CO}, \mathrm{VOC}$, and $\mathrm{PM}$ ) thanks to the electricallydriven heating equipment, which will be partly fed by the PV electricity generated on site and, for the other part, by grid electricity. Figure 9 reports local pollutant emissions for the reference power plant, which are related to the combustion of natural gas in the boiler for space heating and domestic hot water production. $\mathrm{PM}$ and $\mathrm{SO}_{\mathrm{x}}$ emissions are relatively low, thanks to the gaseous nature of the adopted fuel, but $\mathrm{NO}_{\mathrm{x}}$ and VOC reach $30 \mathrm{~kg} /$ year in heating based climate and more than $10 \mathrm{~kg} / \mathrm{year}$ for the other climatic conditions. Boilers also emit a significant amount of CO (between $5 \mathrm{~kg} /$ year and $13 \mathrm{~kg} / \mathrm{year}$ ), due to poorly controlled combustion. Case A has the same local emission levels because it utilizes the same heating equipment of the reference plant. We comment that, fuel combustion for residential heating is a major source of pollution in urban areas (Balaras et al., 2005). We also note that an EURO 6 Diesel passenger car should cover between $200,000 \mathrm{~km}$ and 500,000 $\mathrm{km}$ to emit such an amount of PM, and between 100,000 km and $350,000 \mathrm{~km}$ for what concerns $\mathrm{NO}_{\mathrm{x}}$ (European Parliament, 2016). Boilers CO and VOC emissions are comparatively lower with reference to traffic pollution, yet these are equivalent respectively to $20,000 \mathrm{~km}$, to $60,000 \mathrm{~km}$ and to $30,000 \mathrm{~km}$ to $10,000 \mathrm{~km}$ of a EURO 6 Diesel passenger car. According to (European Automobile Manufacurers Association, 2017), the average annual distance traveled by a car in Europe is about $14,000 \mathrm{~km}$, only part of which in urban areas. Comparing the average car mileage to the emissions of boilers (Reference Case 
and Case A), and considering that the studied building consists of 31 apartments (i.e. 31 families) we conclude that the system configuration of Case $\mathrm{C}$ could significantly contribute to improve the air quality in cities.

The results reported in Figures 5 to 9 clearly evidence that Case $\mathrm{C}$ is the overall best performing plant configuration for all the considered climatic conditions. The PBP ranges from 6 to 7 years and is much lower compared to the expected useful life of the energy system, specifically of the PVs (Reichelstein and Yorston, 2013) that represent the larger investment. Such a remarkable result derives from the synergy between the electrically driven heating, PV electricity production, and thermal energy storage. Thanks to the presence of the HP, the heat storage acts as and electricity storage promoting the self-consumption of locally produced electricity. The HP marginally contributes to the initial investment compared to PV representing between $5 \%$ to $15 \%$ of the capital cost of Case C. On the other hand it has a major impact on the plant economic and environmental performance by further reducing GHG emissions (except for chilling based climate) and avoiding local pollutants. The latter positive effect cannot be achieved by the sole utilization of PVs.

\subsection{Thermal storage, Heat pump, and solar energy integration for Case $C$}

In this section we further dissect the operation of Case $C$, with particular reference to the TES effects, with the aim to identify the specific drivers that promote the positive synergy evidenced in section 4.1 .

Figure 10 compares the consumption from all electrically driven devices with the PV production, for all climatic conditions and on a seasonal basis. Apparently, the electricity produced by the PV plant more than compensates the additional demand generated by the HP for all the climatic conditions. As a partial exception, for the heating based climate, in the colder months the electricity demand of the HP is $11 \%$ higher than the energy produced by the PVs. However, such a difference is more than balanced by the PV production in the warmer months (see Figure 10). As a consequence, for Case C, the energy purchased from the grid is always lower than in the Reference Case (see Figure 6). For warmer climates the solar production is similar to the electricity required by illumination and by the appliances. Figure 10 shows that, during warm seasons, renewable electrical energy exceeds the chilling demand, thus guaranteeing high comfort standards while reducing primary energy demand and GHG and pollutant emissions. Moreover, thanks to the PVs and the TES, thermal and cooling energy productions does not increase the load of the electrical grid.

Figure 10 shows that the operation of the HP and of the TES is particularly critical for the heating based climate during winter months. Figure 11 represents the optimal set-point of the HP for the first 120 days of the year. Similarly, figure 12 reports the thermal energy demand for the same period. In this case, the thermal storage effectively decouples the heat production and consumption, as evidenced by comparing Figure 11 and 12. It promotes the operation of heat pumps at their optimal set-point and during daylight, (see Figure 11) when the external temperature is higher and there is less probability of severe performance derating (see Figure 3). Moreover, the HP is operated at higher load around midday, when the production of the PVs is higher.

Another critical situation is the summer for the chilling based climate due to the very large cooling demand. In this case, a significant part of the PV production cannot be directly utilized to satisfy the chiller demand because production and request are not contemporary, as evidenced by comparing Figure 13 to Figure 14. Such a comparison envisages the possibility to implement also a cooling energy storage.

We recall here that the TES capacity is assumed equivalent to 3 hours of the peak thermal demand, following the results of the analysis performed by (Facci et al., 2014c). To confirm the validity of such an assumption and to further dissect the role of the thermal storage we analyzed the economic performance of the thermal storage varying its capacity from zero to 24 equivalent hours. Figure 15 shows that, if we assume as $100 \%$ the energy cost savings obtainable with a 6 hours thermal storage capacity, $96 \%$ of such cost savings are already achievable with a 3 hours capacity. Moreover, it is also evident that increasing the capacity above 6 hours does not bring significant further energy cost reductions. Thereof, we confirm that 3 hours can be considered an optimal techno-economic compromise for the thermal storage sizing.

The state of charge map throughout the year, reported in Figure 16, clearly emphasizes the role of the thermal storage in heating based climatic conditions. In fact, during fall or winter days, the TES releases heat at night and runs typically out of charge in the early morning hours. It is subsequently refilled by heat pumps at daytime. During spring or summer, the TES is still used to fulfill the heat demand at night, but the state of charge does not usually fall below $50 \%$.

\section{Conclusions}

In this paper we present a study on the optimal integration between photovoltaic electricity production and heating/cooling devices, for the fulfillment of a typical residential energy demand. The study has been performed considering the energy demand from a reference midirise apartment building, under different climatic conditions, and evaluating several power plant configurations with and without the presence of a thermal storage option. For each power plant an optimal control strategy, previously developed and validated by the authors, has been implemented. Electricity selling towards the grid was purposely not admitted, in order to promote the self-consumption of the locally produced renewable energy.

The outcomes from this study shows that the decoupling of heating energy production and consumption, introduced by the thermal storage, has a fundamental role in the optimal power plant operation, both in terms of energy cost savings and GHG emission reduction. Specifically, if heat pumps are used instead of natural gas boilers, an average energy cost reduction of $39 \%$ can be achieved among all climatic conditions ( $41 \%$ peak value in moderate climate), while the average $\mathrm{CO}_{2}$ emission reduction is of $56 \%$ ( $73 \%$ peak value in moderate conditions). Our 
(a) Heating based climate

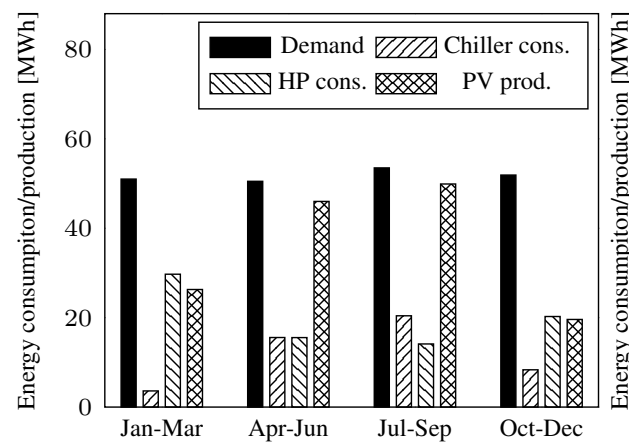

(b) Moderate climate

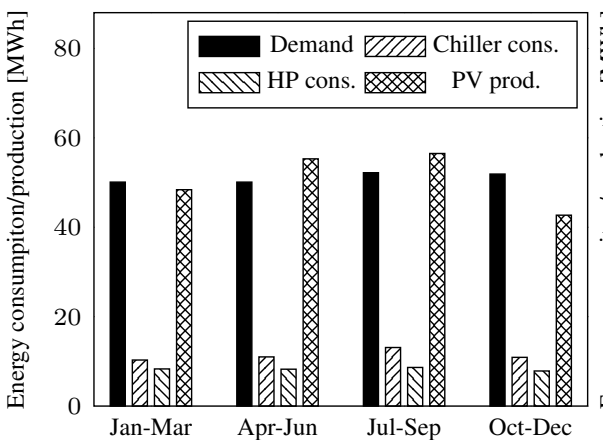

(c) Chilling based climate

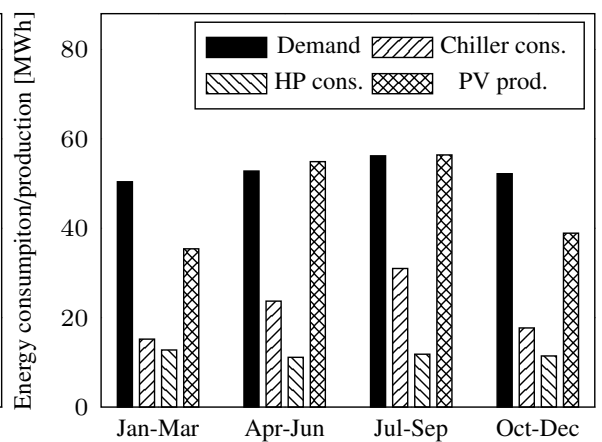

Figure 10: Comparison between seasonal electricity production and consumption for Case C and all the climatic conditions. Note that the energy required by the chillers and heat pumps has been separated from the remaining part of the demand, which is represented by the black bar.

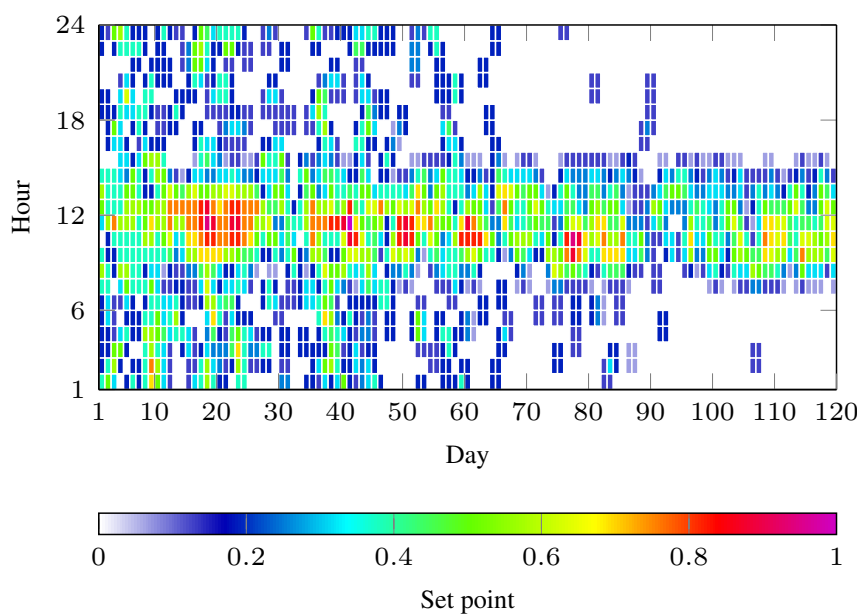

Figure 11: Set point of the HP as a function of the day and the hour for the first 120 days of the year for the heating based climate.

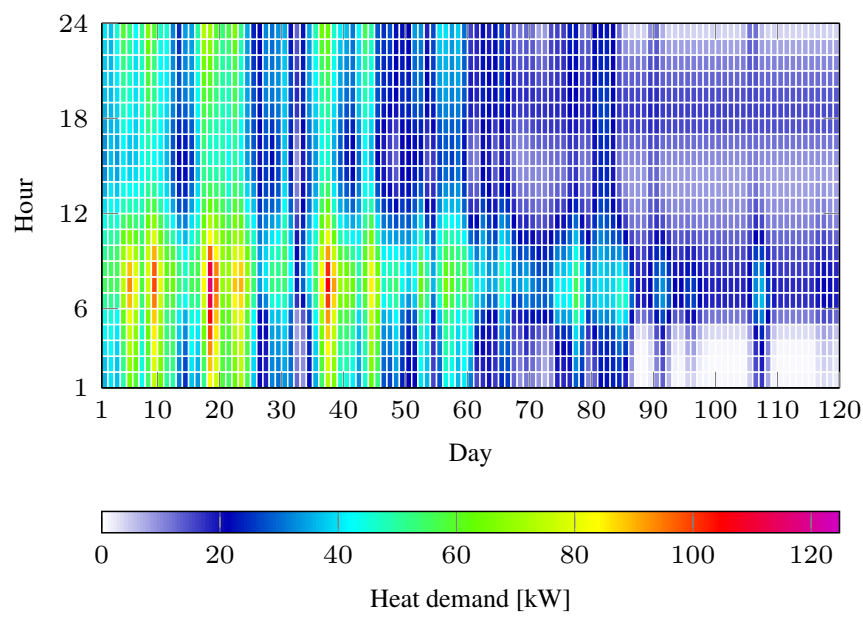

Figure 12: Heat demand as a function of the day and the hour for the first 120 days of the year for the heating based climate.

results demonstrate that an increase in PV installations, if efficiently coupled with electricity based heating, could effectively

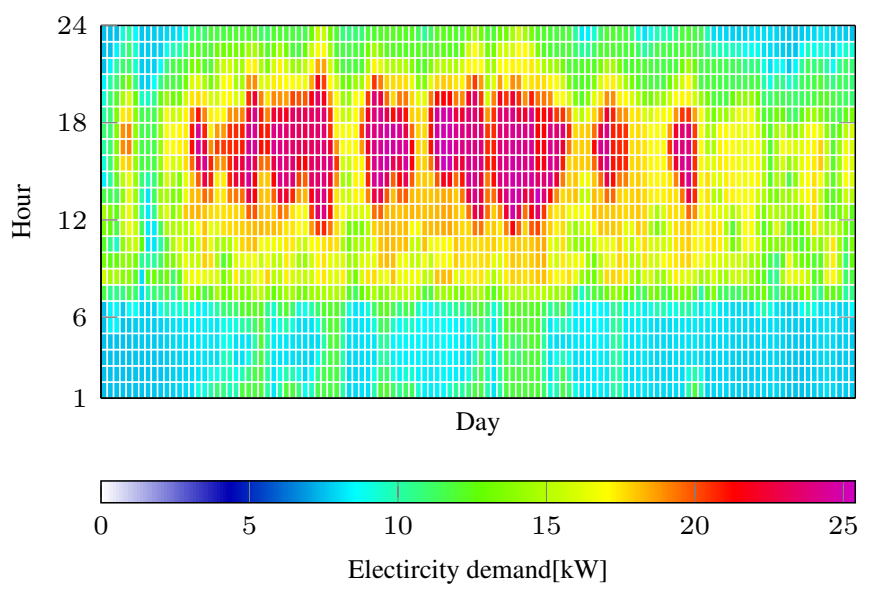

Figure 13: Electricity demand of the chiller as a function of the day and of the hour in summer and for the chilling based climate.

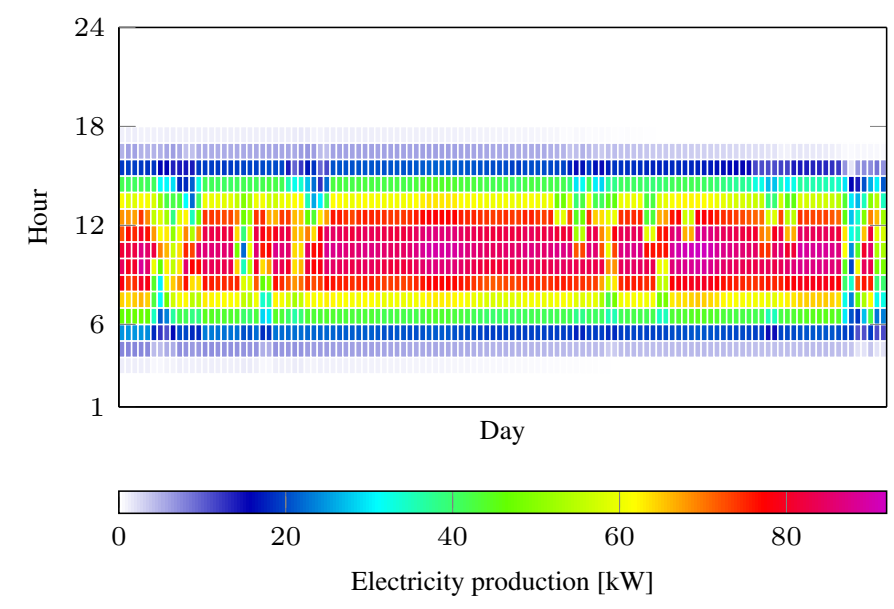

Figure 14: Electricity production of the PV as a function of the day and of the hour in summer for the chilling based climate.

replace natural gas fueled heating in urban areas, with a relatively fast return on investment and with a significant reduction of GHG and local polluting emissions. 


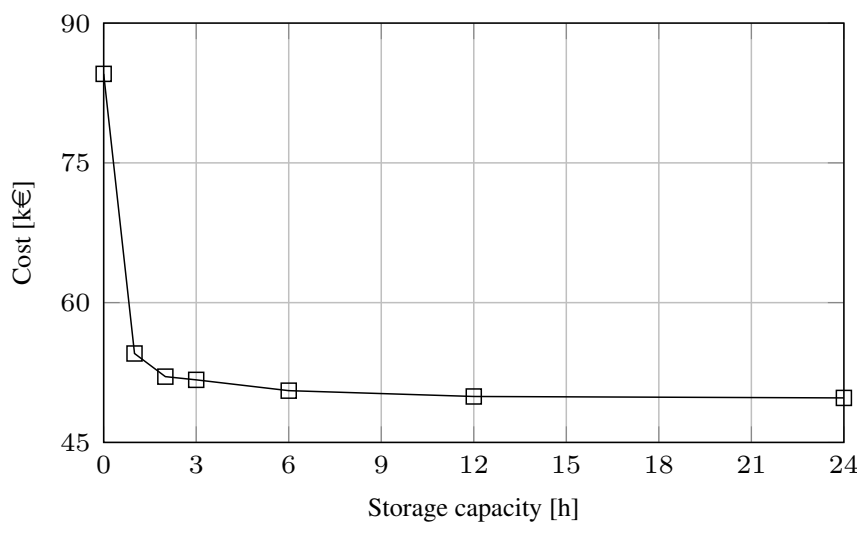

Figure 15: Total energy cost as a function of the capacity of the thermal storage for Case $\mathrm{C}$ and heating based climate.

We note that we did not consider any subsidiary mechanism for RES, such as feed in tariffs, and the result of the paper demonstrate that PVs integrated in a residential buildings does not require specific incentives to be competitive with traditional sources. In fact, the integration of PVs, HPs, and thermal storage guarantees a reasonable PBP, a significant reduction of GHG emissions and totally avoids local pollutant emissions. The key point of such a system is that the thermal storage acts as an electrical storage thanks to the utilization of the HPs, promoting self consumption of electricity. We comment that in many European countries the actual regulation hinders such a positive synergy favoring the selling of the electricity to the grid, and thus requiring feed in tariffs to allow RES to compete with traditional sources. Moreover, a building level micro-grid is required to effectively implement plant configuration $\mathrm{C}$. Such a micro-grid is not permitted in many European legislations. On the other hand, our results clearly shows that legislations should move towards promoting the self consumption of the renewable electricity.

\section{References}

Ackermann, T., Andersson, G., Söder, L., 2001. Distributed generation: a definition. Electric Power Systems Research 57, 195 - 204.

Andreassi, L., Ciminelli, M., Feola, M., Ubertini, S., 2009. Innovative method for energy management: modelling and optimal operation of energy systems. Energy and Buildings 41, 436-444.

Anenberg, S.C., Miller, J., Minjares, R., Du, L., Henze, D.K., Lacey, F., Malley, C.S., Emberson, L., Franco, V., Klimont, Z., Heyes, C., 2017. Impacts and mitigation of excess diesel-related NOx emissions in 11 major vehicle markets. Nature 545, 467-471.

Arce, P., Medrano, M., Gil, A., Oró, E., Cabeza, L.F., 2011. Overview of thermal energy storage (TES) potential energy savings and climate change mitigation in Spain and Europe. Applied energy 88, 2764-2774.

Arden Pope III, C., Ezzati, M., Dockery, D.W., 2009. Fine-particulate air pollution and life expectancy in the United States. The New England Journal of Medicine 360, 376-386.

Arteconi, A., Hewitt, N.J., Polonara, F., 2013. Domestic demand-side management (dsm): Role of heat pumps and thermal energy storage (tes) systems. Applied thermal engineering 51, 155-165.

Balaras, C.A., Droutsa, K., Dascalaki, E., Kontoyiannidis, S., 2005. Heating energy consumption and resulting environmental impact of european apartment buildings. Energy and Buildings 37, 429-442.
Balke, J., 2014. Integration of Renewable Energy in Europe. Technical Report 9011-700. European Energy Agency.

Beaudin, M., Zareipour, H., Schellenberglabe, A., Rosehart, W., 2010. Energy storage for mitigating the variability of renewable electricity sources: An updated review. Energy for Sustainable Development 14, 302-314.

Candelise, C., Winskel, M., Gross, R.J., 2013. The dynamics of solar PV costs and prices as a challenge for technology forecasting. Renewable and Sustainable Energy Reviews 26, 96-107.

Cappa, F., Facci, A.L., Ubertini, S., 2015. Proton exchange membrane fuel cell for cooperating households: A convenient combined heat and power solution for residential applications. Energy 90, 1229-1238.

Chiappini, D., Facci, A.L., Tribioli, L., Ubertini, S., 2011. SOFC management in distributed energy systems. Journal of Fuel Cell Science and Technology 8 .

Chicco, G., Mancarella, P., 2009. Distributed multi-generation: A comprehensive view. Renewable and Sustainable Energy Reviews 13, 535 - 551.

Cozzolino, R., Tribioli, L., Bella, G., 2016. Power management of a hybrid renewable system for artificial islands: A case study. Energy 106, 774-789.

Daikin, 2015. VRV Catalogo Prodotti. Daikin.

Dodds, P.E., Staffell, I., Hawkes, A.D., Li, F., Grünewald, P., McDowall, W., Ekins, P., 2015. Hydrogen and fuel cell technologies for heating: a review. International Journal of Hydrogen Energy 40, 2065-2083.

Dows, R.N., Gough, E.J., 1996. PVUSA procurement, acceptance, and rating practices for photovoltaic power plants. Technical Report 95-30910000.1. Pacific Gas and Electric Company.

European Automobile Manufacurers Association, 2017. Cars, Trucks \& the Environment.

European Commission, 2016. Buildings.

European Environment Agency, 2014. Trends and projections in Europe. Technical Report 6/2014. European Environment Agency.

European Environment Agency, 2015. Renewable energy in Europe - approximated recent growth and knock-on effects. Technical Report 1/2015. European Environment Agency.

European Environmental Agency, 2012. Households and industry responsible for half of eu greenhouse gas emissions from fossil fuels.

European Parliament, 2016. Regulation (EC) No 715/2007 of the European Parliament and of the Council of 20 June 2007 on type approval of motor vehicles with respect to emissions from light passenger and commercial vehicles (Euro 5 and Euro 6) and on access to vehicle repair and maintenance information (Text with EEA relevance).

Eurostat, 2009. Panorama of energy. Energy statistics to support EU policies and solutions. Eurostat.

Eurostat, 2016. Eurostat, your key to european statistics.

Fabrizio, E., Filippi, M., Virgone, J., 2009. An hourly modelling framework for the assessment of energy sources exploitation and energy converters selection and sizing in buildings. Energy and Buildings 41, 1037-1050.

Facci, A.L., Andreassi, L., Martini, F., Ubertini, S., 2014a. Comparing energy and cost optimization in distributed energy systems management. Journal of Energy Resources Technology 136, 032001.

Facci, A.L., Andreassi, L., Ubertini, S., 2014b. Optimization of CHCP (combined heat power and cooling) systems operation strategy using dynamic programming. Energy 66, 387-400.

Facci, A.L., Andreassi, L., Ubertini, S., Sciubba, E., 2014c. Analysis of the influence of thermal energy storage on the optimal management of a trigeneration plant. Energy Procedia 45, 1295-1304.

Facci, A.L., Cigolotti, V., Jannelli, E., Ubertini, S., 2016. Technical and economic assessment of a SOFC-based energy system for combined cooling, heating and power. Applied Energy .

Facci, A.L., Martini, F., Pirozzi, S., Zanfardino, A., Ubertini, S., 2015. Control strategy optimization of HVAC plants, in: AIP Conference Proceedings, AIP Publishing. p. 570004.

Fraga, C., Hollmuller, P., Mermoud, F., Lachal, B., 2017. Solar assisted heat pump system for multifamily buildings: Towards a seasonal performance factor of 5 ? numerical sensitivity analysis based on a monitored case study. Solar Energy 146, 543-564.

Franco, A., Salza, P., 2011. Strategies for optimal penetration of intermittent renewables in complex energy systems based on techno-operational objectives. Renewable Energy 36, 743 - 753.

Frondel, M., Ritter, N., Schmidt, C.M., Vance, C., 2010. Economic impacts from the promotion of renewable energy technologies: The german experience. Energy Policy 38, 4048-4056. 


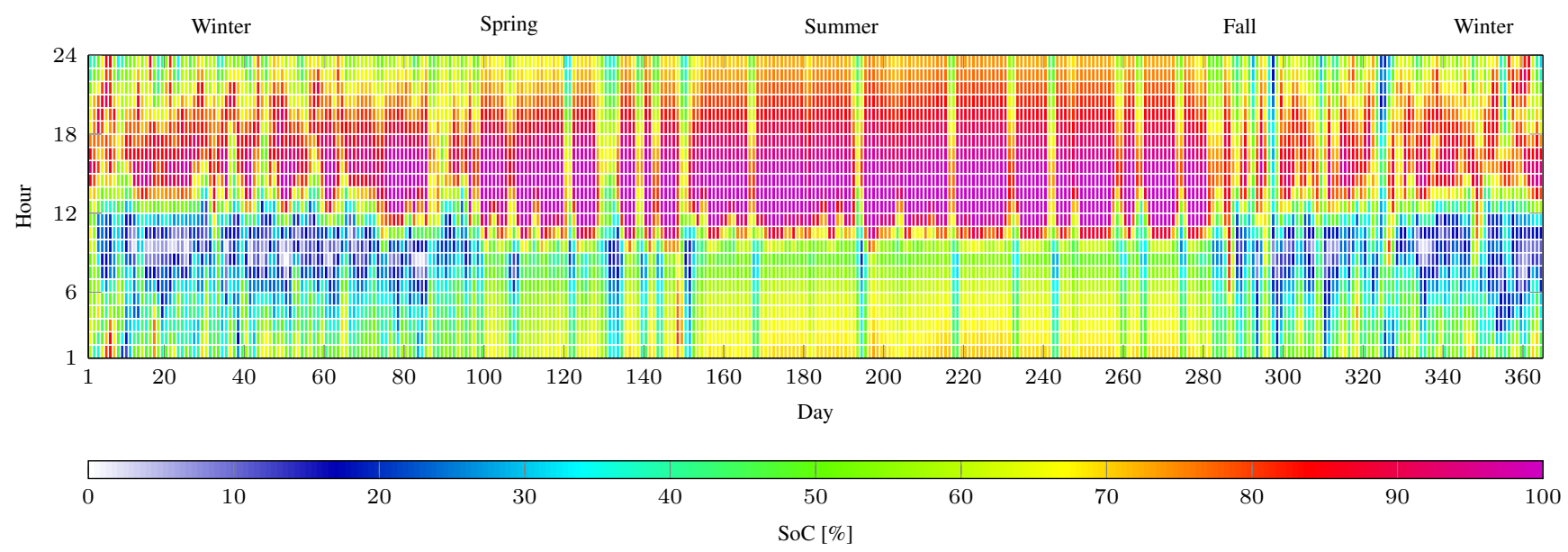

Figure 16: State of charge of the thermal storage as a function of time for Case $\mathrm{C}$ and heating based climate.

GME, 2016. historical data day ahead market.

Hasnain, S., 1998. Review on sustainable thermal energy storage technologies, part i: heat storage materials and techniques. Energy conversion and management 39, 1127-1138.

Hawkes, A., Leach, M., 2007. Cost-effective operating strategy for residential micro-combined heat and power. Energy 32, 711-723.

Hittinger, E., Whitacre, J., Apt, J., 2012. What properties of grid energy storage are most valuable? Journal of Power Sources 206, 436-449.

IEA-IRENA, 2013. Thermal Energy Storage Technology Brief. IEA-IRENA. International Energy Agency, 2017a. Key world energy statistics.

International Energy Agency, 2017b. World energy balances overview.

Jannelli, E., Minutillo, M., Cozzolino, R., Falcucci, G., 2014a. Thermodynamic performance assessment of a small size CCHP (combined cooling heating and power) system with numerical models. Energy 65, 240-249.

Jannelli, E., Minutillo, M., Lavadera, A.L., Falcucci, G., 2014b. A small-scale caes (compressed air energy storage) system for stand-alone renewable energy power plant for a radio base station: A sizing-design methodology. Energy 78, 313-322.

Jelle, B.P., Breivik, C., Røkenes, H.D., 2012. Building integrated photovoltaic products: A state-of-the-art review and future research opportunities. Solar Energy Materials and Solar Cells 100, 69-96.

Jonas, D., Frey, G., Theis, D., 2017. Simulation and performance analysis of combined parallel solar thermal and ground or air source heat pump systems. Solar Energy 150, 500-511.

Kaldellis, J., Zafirakis, D., 2007. Optimum energy storage techniques for the improvement of renewable energy sources-based electricity generation economic efficiency. Energy 32, 2295-2305.

Lau, K., Yousof, M., Arshad, S., Anwari, M., Yatim, A., 2010. Performance analysis of hybrid photovoltaic/diesel energy system under malaysian conditions. Energy 35, 3245 - 3255.

Laustsen, M.J., 2008. Energy efficiency requirements in building codes, energy efficiency policies for new buildings.

Li, Y.H., Kao, W.C., 2017. Performance analysis and economic assessment of solar thermal and heat pump combisystems for subtropical and tropical region. Solar Energy 153, 301-316.

Marano, V., Rizzo, G., Tiano, F.A., 2012. Application of dynamic programming to the optimal management of a hybrid power plant with wind turbines, photovoltaic panels and compressed air energy storage. Applied Energy 97, 849-859. Energy Solutions for a Sustainable World - Proceedings of the Third International Conference on Applied Energy, May 16-18, 2011 - Perugia, Italy.

Mitsubishi Electric, 2017. PV-MLU250HC Photovoltaic Module specification sheet.

Moro, A., Lonza, L., 2017. Electricity carbon intensity in european member states: Impacts on GHG emissions of electric vehicles. Transportation Research Part D: Transport and Environment .

Navarro, L., de Gracia, A., Colclough, S., Browne, M., McCormack, S.J., Griffiths, P., Cabeza, L.F., 2016a. Thermal energy storage in building integrated thermal systems: A review. part 1. active storage systems. Renewable Energy $88,526-547$.

Navarro, L., de Gracia, A., Niall, D., Castell, A., Browne, M., McCormack, S.J., Griffiths, P., Cabeza, L.F., 2016b. Thermal energy storage in building integrated thermal systems: A review. part 2. integration as passive system. Renewable Energy 85, 1334-1356.

Office of Energy Efficiency and Renewable Energy, 2016. Commercial reference buildings. http://energy.gov/eere/buildings/commercial-referencebuildings.

Onovwiona, H., Ugursal, V., 2006. Residential cogeneration systems: review of the current technology. Renewable and Sustainable Energy Reviews 10, $389-431$.

Paatero, J.V., Lund, P.D., 2007. Effects of large-scale photovoltaic power integration on electricity distribution networks. Renewable Energy 32, 216-234.

Paul, K., 2017. National Survey Report of PV Power Applications in France 2016. Technical Report. IEA International Energy Angency.

Peng, C., Huang, Y., Wu, Z., 2011. Building-integrated photovoltaics (BIPV) in architectural design in china. Energy and Buildings 43, 3592-3598.

Photovoltaic geographical information system , 2017.

Poullikkas, A., 2013. A comparative overview of large-scale battery systems for electricity storage. Renewable and Sustainable Energy Reviews 27, 778788 .

Ragwitz, M., Steinhilber, S., 2014. Effectiveness and efficiency of support schemes for electricity from renewable energy sources. Wiley Interdisciplinary Reviews: Energy and Environment 3, 213-229.

Reichelstein, S., Yorston, M., 2013. The prospects for cost competitive solar PV power. Energy Policy 55, 117 - 127. Special section: Long Run Transitions to Sustainable Economic Structures in the European Union and Beyond.

Sari, D., Bayram, A., 2014. Quantification of emissions from domestic heating in residential areas of Izmir, Turkey and assessment of the impact on local/regional air-quality. Science of the Total Environment 488, 429-436.

The European Parliament and the Council of the European Union, 2012. Directive 2012/27/eu of the European Parliament and of the Council of 25 October 2012 on energy efficiency, amending directives 2009/125/ec and 2010/30/eu and repealing directives 2004/8/ec and 2006/32/ec. Official Journal of the European Union .

Tilli, F., Maugeri, G., Castello, S., 2017. National Survey Report of PV Power Applications in Italy - 2016. Technical Report. IEA International Energy Angency.

Tribioli, L., Cozzolino, R., Evangelisti, L., Bella, G., 2016. Energy management of an off-grid hybrid power plant with multiple energy storage systems. Energies 9, 661.

Tsikaloudaki, K., Laskos, K., Bikas, D., 2011. On the establishment of climatic zones in Europe with regard to the energy performance of buildings. Energies 5, 32-44.

UNEF, 2017. National Survey Report of PV Power Applications in Spain 2016. Technical Report. IEA International Energy Angency.

UNFCCC, 2017. United Nations framework Convention on climate change. 
United States Environmental Protection Agency, 2017. Air emissions factors and quantification.

US Department of Energy, 2012. Buildings energy data book.

Youssef, W., Ge, Y., Tassou, S., 2017. Effects of latent heat storage and controls on stability and performance of a solar assisted heat pump system for domestic hot water production. Solar Energy 150, 394-407. 